\title{
Option Pricing Kernels and the ICAPM
}

\author{
Michael J. Brennan* \\ Xiaoquan Liu ${ }^{\dagger}$ \\ Yihong $\mathrm{Xia}^{\ddagger}$
}

July 11, 2006

\footnotetext{
*Finance Department, the Anderson School, UCLA, 110 Westwood Plaza, Los Angeles, CA 90095-1481. Email: michael.brennan@anderson.ucla.edu.

${ }^{\dagger}$ Department of Accounting, Finance, and Management, University of Essex, Colchester, CO4 3SQ, UK. E-mail: liux@essex.ac.uk.

${ }^{\ddagger}$ Finance Department, The Wharton School, University of Pennsylvania, Philadelphia, PA 19104-6367.
} 


\begin{abstract}
We estimate the parameters of pricing kernels that depend on both aggregate wealth and state variables that describe the investment opportunity set, using FTSE 100 and S\&P 500 index option returns as the returns to be priced. The coefficients of the state variables are highly significant and remarkably consistent across specifications of the pricing kernel, and across the two markets. The results provide further evidence that, consistent with Merton's (1973) Intertemporal Capital Asset Pricing Model, state variables in addition to market risk are priced.
\end{abstract}




\section{Introduction}

The failure of simple complete markets option pricing models of the BlackScholes (1973) type points to the importance in option pricing of state variables other than the underlying asset price. Despite increasing evidence that state variables other than the market index are important for pricing both equity and equity index option returns, and despite the fact that these securities are traded in integrated capital markets, the role of state variables that have been found useful in pricing equities has yet to be examined in option pricing. ${ }^{1}$

This paper bridges the gap by investigating the role in option pricing of state variables that have been found important in pricing equities. Because there is considerable debate among researchers over the state variables that enter into the pricing kernel, we start with the simple ICAPM pricing kernel developed by Brennan, Wang, and Xia (2004) (BWX) that prices bonds and stocks. In this parsimonious setting, time variation in the instantaneous investment opportunity set is fully described by the dynamics of the real interest rate $r$, and the maximum Sharpe ratio $\eta$, and their current values are sufficient statistics for all future investment opportunities. As a result, these are the only state variables that are priced. BWX show that this simple ICAPM outperforms the Fama-French (1995) three-factor model in pricing size and book-to-market sorted portfolios of common stocks, and that both $r$ and $\eta$ risks are associated with significant risk premia. Therefore, the real interest rate and the maximum Sharpe ratio are natural variables to include in the option pricing kernel, in addition to aggregate wealth.

In the option pricing literature, there is growing evidence that volatility is a priced factor in option returns. Bakshi and Kapadia (2003) examine the time series and cross sectional properties of the returns on delta hedged portfolios with a long position in options and a short position in stocks . The portfolio returns are significantly negative, implying a negative premium for volatility risk. Similarly, Buraschi and Jackwerth (1999), Chernov et. al. (2003), Coval and Shumway (2001), Driessen and Maenhout (2003), and Pan (2002) have all found that volatility is priced. In particular, Coval and Shumway (2001) conclude that "something besides market risk is important for pricing the risks associated with option contracts," and suggest that stochastic volatility may be an important factor for asset pricing.

\footnotetext{
${ }^{1}$ Vanden (2004) constructs an asset pricing model with wealth constraints, in which option returns enter the pricing kernel for stocks.
} 
More generally, Mayfield (2004) has constructed an equilibrium regime switching model in which volatility is priced. Volatility is found to be associated (negatively) with the favorableness of investment opportunities, as measured by the Sharpe ratio. More recently, Tauchen (2005) examines the relationship between market volatility and returns in the context of a general equilibrium framework. He generates a two-factor structure for volatility, along with time-varying risk premiums on consumption and volatility risk. In light of this theoretical and empirical evidence on the role of volatility, we include a measure of volatility as an additional state variable in the pricing kernel.

Most prior studies that extract a pricing kernel from the observed prices of index options rely on a parameterization of the stochastic process for the underlying index. For example, Rosenberg and Engel (2002) assume that the index follows a GARCH process, and Pan (2002) and Santa-Clara and Yan (2004) assume that it follows a mixed jump-diffusion process. While a parametric assumption of the underlying asset dynamics lends power to the estimation, it also raises the possibility of mis-specification. In this paper, we estimate the pricing kernel by applying the Generalized Method of Moment (GMM) to option returns, which avoids the need to rely on any specific option pricing model or specific assumptions about the stochastic processes for the underlying asset returns. Both Buraschi and Jackwerth (1999) and Coval and Shumway (2001) have previously applied GMM to option returns.

We estimate separate pricing kernels for the UK and US. ${ }^{2}$ Our primary options data are monthly returns on 11 put and call option portfolios on the FTSE 100 index for the period from April 1992 to March 2002, and 10 put and call portfolios on the S\&P 500 index for the period from January 1992 to April 2002. The portfolios consist of options that have between 1 and 2 months to maturity and between 2 and 3 months to maturity at the time of portfolio formation, and are formed on the basis of option type, time to maturity, and moneyness.

The empirical proxies that we use for the arguments of the pricing kernel are as follows. The return on aggregate wealth is taken as the return on a broad index of market returns: FTSE 250 value-weighted index for the UK and the CRSP value-weighted index for the US. The time series of the real interest rate $r$, and maximum Sharpe ratio $\eta$, together with the expected rate of inflation $\pi$, are estimated by Brennan and Xia (2006) (BX) from panel data

\footnotetext{
${ }^{2}$ Brennan and Xia (2006) discuss the theoretical relation between the pricing kernels for different currencies and present empirical evidence for several pairs of currency.
} 
on zero-coupon government bond yields within an essentially affine pricing model framework. The proxy for our final state variable, volatility, is a measure of the volatility implied by option prices.

When the pricing kernel is constrained to be a power function of the return on aggregate wealth, the estimated coefficient of relative risk aversion for the UK (FTSE 100 options) is found to be negative. However, the estimated coefficient of relative risk aversion becomes positive (but not statistically significant) when the pricing kernel specification is augmented by the state variables $r, \eta$, and $\sigma$. For the US (S\&P 500 options), the estimated coefficient of relative risk aversion is 2.7 when no state variables is included, and 4.8 when all the state variables are included. Only the coefficient of the innovation in the real interest rate is significant in the UK, while the coefficients of all three state variables are significant in the US. The signs of the coefficients on the state variables are the same for the US and UK.

It is possible that the significance of the state variables is induced by the restrictive functional form of the kernel on the return on aggregate wealth. Therefore the kernel is next written as the product of a polynomial in the return on aggregate wealth and an exponential affine function of the state variables. When $r$ and $\eta$ are the only state variables, the coefficients of both variables are significant for both US and $\mathrm{UK}^{3}$ moreover, the signs of the coefficients are the same for the two countries, and are consistent with the estimates of the risk premia for these variables obtained by BWX (2004, Table II) using returns on size and book-to-market sorted portfolios of US common stocks. They are also consistent with the correlations between these variables and the pricing kernels that are estimated using the government bond yield data by BX.

When an estimate of the implied volatility, $\sigma$, is added to the pricing kernel specification, its coefficient is significant and positive for both countries: the sign of the coefficient is consistent with prior studies by Coval and Shumway (2001) and Bakshi and Kapadia (2003) that report a negative volatility risk premium. Introducing the implied volatility makes the coefficient of $\eta$ insignificant for the UK but makes no material difference for the US.

While the coefficients of the state variables in the pricing kernel are not restricted by theory, we find striking consistency between: first, the signs of the coefficients of the state variables in the pricing kernel for the two countries estimated using the option returns in this paper; second, the signs

\footnotetext{
${ }^{3}$ The finding of a significant risk premium associated with $r$ contrasts with Pan (2002), who explicitly assumes that interest rate risk is not priced.
} 
of the correlations of the state variables with the pricing kernel estimated using the bond yield data by BX; and third, the risk premia for the state variables estimated using US equity returns by BWX. ${ }^{4}$

The over-identifying restrictions of the estimation are rejected, which may in part due to our small sample. But the general consistency in the estimated coefficients of the pricing kernel, not only across markets and countries, but also across different model specifications, attests to the importance of including these state variables that capture time-variation in the investment opportunity set in the pricing kernel for risky securities.

The rest of the paper is organized as follows. Section 2 discusses option pricing in terms of the pricing kernel. Section 3 describes the data. The main empirical results are presented in Section 4. Finally, Section 5 concludes.

\section{Option Prices and the Pricing Kernel}

It is well known that the assumption of no arbitrage is equivalent to the existence of a pricing kernel, $m$, such that for any security return, $\tilde{R}_{t+1}:^{5}$

$$
E\left[m_{t+1}\left(1+\tilde{R}_{t+1)}\right) \mid I_{t}\right]=1
$$

where $\tilde{R}_{t+1}$ is the rate of return from $t$ to $t+1$, and $I_{t}$ denotes the information available at time $t$. In general, the pricing kernel is a function of a vector of state variables $X$.

When pricing contingent claims on an underlying asset $S$, it is often convenient to project the pricing kernel $m$ onto the space of the underlying asset returns. Cochrane (2001) shows that the projected pricing kernel, $m^{*}$, has the same pricing implications for payoffs as does the original pricing kernel. In a Black-Scholes economy in which the (continuously compounded) interest rate $r$ is a constant, and the price of the underlying asset $S$ follows a geometric Brownian Motion, the (projected) pricing kernel for all contingent claims can be written as the product of a power function of the underlying asset return and a function of time $t$ as shown in Bick (1987): $m^{*}=(1+\tilde{R})^{-\gamma} e^{-r}$. Rubinstein (1976) and Brennan (1979) show that a stochastic discount factor of this form yields Black-Scholes pricing in a discrete time setting if security returns are lognormal. If the Black-Scholes

\footnotetext{
${ }^{4}$ This form of pricing kernel has not been estimated using UK equity returns.

${ }^{5}$ Campbell et al. (1997) and Cochrane (2001) discuss the role of the pricing kernel in asset pricing.
} 
assumptions are not satisfied, a projection of the true pricing kernel onto the asset return space is still feasible, but the projection may take a general and unknown functional form.

In studying the prices of options on a market index, it is common to estimate only the projection of the pricing kernel onto the space of the underlying index returns. For example, Ait-Sahalia and Lo (2000), Jackwerth (2000), and Rosenberg and Engle (2002) use equity index option prices to estimate the projections of pricing kernels onto S\&P 500 returns. Since the pricing kernel projection is a univariate function of the index returns, it does not allow for an explicit examination of other state variables that may enter the pricing kernel.

In this paper, we estimate a pricing kernel which is motivated by the Intertemporal Capital Asset Pricing Model of Merton (1973) and contains variables that capture the time variation in investment opportunities. BWX and Nielsen and Vassalou (2005) argued that, in a diffusion setting, if the interest rate $r$ and the maximal Sharpe ratio $\eta$ follow a joint Markov process, then they are sufficient statistics for investment opportunities, and therefore, along with the wealth of the representative agent, natural candidates as arguments of the pricing kernel in an ICAPM setting. BWX report that both state variables command significant risk premia and play important roles in the pricing of cross-sectional size and book-to-market sorted equity portfolio returns. Note that, if the state variables, $X \equiv(r, \eta)$, are not independent of the aggregate wealth, there is no reason to expect the projection of the pricing kernel onto the aggregate wealth to retain the power function form even if the representative agent's utility of consumption is iso-elastic.

Motivated by the BWX model, we shall first assume that the stochastic discount factor can be written as the product of a power function of the aggregate wealth return $R_{W}$, and an exponential affine function of the change in state variables $r$ and $\eta$ :

$$
m_{t+1}=g\left(R_{W, t+1}\right) \exp ^{c_{1} \Delta r_{t+1}+c_{2} \Delta \eta_{t+1}}
$$

$g\left(R_{W, t+1}\right)$ is a monotone decreasing function, reflecting the declining marginal utility of wealth. In our empirical analysis we shall consider a standard power specification, $g\left(R_{W, t+1}\right)=c_{0}\left(1+R_{W, t+1}\right)^{-\gamma}$ where $c_{0}>0$, and $\gamma$, the coefficient of relative risk aversion, is greater than zero. We shall also consider a more general specification in which $g\left(R_{W, t+1}\right)$ is a Chebyshev polynomial in the return on aggregate wealth. The exponential function 
ensures that the pricing kernel cannot be negative. We shall later consider additional potential state variables within this exponential affine framework.

The definition of $m_{t+1}$ together with equation (1) implies that, for any security $i$, the following moment condition holds:

$$
E\left[g\left(R_{W, t+1}\right) \exp ^{c_{1} \Delta r_{t+1}+c_{2} \Delta \eta_{t+1}}\left(1+\tilde{R}_{i, t+1}\right) \mid I_{t}\right]=1 .
$$

If $z_{t}$ is an instrumental variable in the current information set $I_{t}$, then the above Euler equation implies the unconditional moment condition:

$$
E\left[g\left(R_{W, t+1}\right) \exp ^{c_{1} \Delta r_{t+1}+c_{2} \Delta \eta_{t+1}}\left(1+\tilde{R}_{i, t+1}\right) z_{t}\right]=E\left(z_{t}\right), \quad \forall z_{t} \in I_{t}
$$

We shall estimate the parameters of the pricing kernel, including $c_{1}$ and $c_{2}$, by GMM using moment conditions (3)-(4), where the set of asset returns, $R_{i}$, consists of returns on index option portfolios, the returns on aggregate wealth, and Treasury Bill rates.

The BWX model assumes that both the real interest rate and the Sharpe ratio follow univariate Ornstein-Uhlenbeck processes. This is obviously a strong assumption, and Brandt and Kang (2004) present evidence which suggests that the Sharpe ratio (of the equity market) follows a two-factor process with the second factor being the market volatility $\sigma$. Under this specification of the dynamics of the Sharpe ratio, the level of market volatility, $\sigma$, also becomes a state variable that is required to fully describe the investment opportunity set. ${ }^{6}$ Therefore, we shall include $\sigma$ in the set of state variables, $X$, which describe the pricing kernel. However, for analytical tractability we shall treat $\sigma$ as constant when we estimate the time series of the other two state variables, $r$ and $\eta$, from panel data on Treasury Bond yields.

\section{Data}

The primary data are the prices of European put and call options on the FTSE 100 index traded on the London International Financial Futures and

\footnotetext{
${ }^{6}$ Note that $\sigma$ is not necessary to describe the instantaneous myopic investment opportunity set, which is fully captured by $(r, \eta)$. However, it may be necessary to capture the dynamics of the myopic investment opportunity set.
} 
Options Exchange (LIFFE), and the prices of European put and call options on the S\&P 500 index traded on the Chicago Board Options Exchange (CBOE). We collect prices on the second (or the closest to the second) trading day of each month from April 1992 to March 2002 for the UK and from January 1992 to April 2002 for the US ${ }^{7}$, on options that have maturities of less than three months. For each option that has a price on the second trading day of the current month and on the second trading day of the following month, a return for the month is calculated as the proportional price change between these dates. Put and call options are assigned to portfolios on the basis of their time to maturity and moneyness. The ' 1 month' portfolios contain options that have between 1 and 2 months to expiration at the portfolio formation date at the beginning of the month, and the '2-month' portfolios contain options that have between 2 and 3 months to expiration at the portfolio formation date. For each maturity, 7 portfolios of calls and of puts are formed according to moneyness. Portfolio 1 consists of deep out-of-the-money options, whose moneyness is no greater than $15 \%$; for portfolio 2 , the moneyness is between $-15 \%$ and $-10 \%$; portfolio 3 between $-10 \%$ and $-5 \%$; portfolio 4 between $-5 \%$ and 0 ; portfolio 5 between 0 to $5 \%$ in-the-money; portfolio 6 between $5 \%$ and $10 \%$; and for portfolio 7 , it is greater than $10 \%$ in-the-money. Summary statistics on the portfolios are presented in Table 1.

The deep out-of-the-money call portfolios (low numbered portfolios) have negative average returns; the average return on 1-month calls that are between 5 and $10 \%$ out of the money is minus $29 \%$ per month for the UK and minus $3 \%$ per month for the US, which contrasts with a return of $1.48 \%$ per week reported by Coval and Shumway (2001) for similar (American) contracts on the SPX index for the period 1990-1995; the corresponding figures for 2 -month calls are minus $15 \%$ per month and minus $7 \%$ per month. The returns to the deep out-of-the-money call portfolios are highly skewed. The in-the-money call portfolios have slightly positive average returns and virtually no skewness. The same convention was followed in constructing the portfolios of puts so that portfolio 1 contains the deep out of the money options, and portfolio 7 the deep in the money options. As with the calls, the deep out of the money puts have strongly negative returns: the portfolio of 1-month puts that is between 10 and $15 \%$ out of the money loses an average of $29 \%$ per month for the UK and $64 \%$ per month for the US.

Not all of the moneyness buckets contain traded options each month. For

\footnotetext{
${ }^{7}$ We thank Jens Jackwerth for kindly providing us the US option data from 1992 to 1995. The data from 1996 to 2002 are collected from OptionMetrics.
} 
example, there are 98 out of 120 months for the UK when there is no 1-month call option that is more than $15 \%$ out of the money. Our main analysis will be conducted using the portfolios for which there are essentially no missing observations. For the UK we use 11 portfolios that have no missing observations, which include two 1-month call portfolios, two 1-month put portfolios, three 2-month call portfolios, and four 2-month put portfolios. For the US we use 10 portfolios that have no more than 2 (out of 123) missing observations, which include three 1-month call portfolios, three 1month put portfolios, two 2-month call portfolios, and two 2-month put portfolios.

We shall use as our measure of market volatility, $\sigma$, an estimate of the implied volatility of option prices. For the UK this is obtained by first calculating the average implied volatility for each of the one month option portfolios and then averaging these values. For the US the implied volatility is taken as the VIX index. ${ }^{8}$ The nominal interest rate, $R_{f}$, for the UK is the 1-month Treasury Bill rate reported by the Bank of England, and for the US is the 30-day Treasury Bill rates obtained from CRSP. The return on aggregate wealth for the UK is taken as the return on the FTSE 250 index, which is a value-weighted index of UK equities. Note that this is a broader index than the FTSE 100 on which the options are written. We choose the FTSE 250 as the market index because it is a better proxy for the return on aggregate wealth. For the US the return on aggregate wealth is taken as the CRSP value-weighted index return.

Following BWX, the empirical estimates of the state variables $(r, \eta, \pi)$ come from BX. For the UK, they are derived from the zero coupon bond yields for the second trading day of each month from January 1985 to May 2002 for maturities of 1, 2, 3, 5, 7, 10 and 15 years reported by the Bank of England. For the US, they are estimated from zero coupon bond prices of US Treasury Bonds using a cubic spline. ${ }^{9}$. Inflation rates were calculated from Consumer Price Index data reported by DataStream.

\footnotetext{
${ }^{8}$ VIX is the CBOE volatility index and measures market expectations of volatility over the next 30 days as conveyed by stock index option prices. VIX estimates expected volatility from the prices of $\mathrm{S} \& \mathrm{P} 500$ index options.

${ }^{9}$ Further details are available in Brennan and Xia (2006)
} 


\section{Empirical Results}

Table 2 provides summary statistics for the variables that we consider as arguments of the pricing kernel and as instruments in our estimation. Panel A tabulates the mean, standard deviation, and skewness of the level and the innovations of the state variables, the market returns, and the riskfree rate. Panel B reports the contemporaneous correlations between the innovations of the state variables and the market return. Panel C, which comes from Table 3 in Brennan and Xia (2006), reports correlations between the state variables themselves and between the state variables and the equity market pricing kernel. Note that in both the US and the UK, the correlation between $r$ and the pricing kernel is positive and significant, and the correlation between $\eta$ and the pricing kernel is negative and significant. ${ }^{10}$

Some of the correlations between the changes in the state variables and the return on aggregate wealth are quite significant. A regression of the aggregate wealth return on changes in $r, \pi, \eta, \sigma$ yields a value of $R^{2}$ of $29 \%$ for the UK and $27.5 \%$ for the US. Therefore, even if $g\left(R_{W}\right)$ is a power function, if the true pricing kernel is of the form (2), it is unlikely that the projection of the kernel onto the space of aggregate wealth returns will yield a simple iso-elastic function. This may account for the non-monotonicity (absence of local risk aversion) as well as the time variation in the pricing kernel projections estimated by Rosenberg and Engle (2002) and Jackwerth (2000), among others. We shall examine this issue later.

In order to identify the coefficients of the pricing kernel it is necessary that the loadings of the option portfolio returns on the pricing kernel variables not be zero. Table 3 reports the results of seemingly unrelated regressions of the monthly returns on the option portfolios on the market return and changes $r, \eta$, and $\sigma$. Panel A reports the coefficients for the 1-month option portfolio returns for the two markets, and Panel B for the 2-month option portfolios. The loadings of the portfolio returns vary considerably with both moneyness and maturity. For the UK a likelihood test easily rejects the null hypotheses that the coefficients are equal to zero for each of $\Delta r, \Delta \eta$ and $\Delta \sigma$ separately. For the US, when we use all the option returns, we can reject the null hypothesis only for the coefficient of $\Delta \sigma$. We conjecture that the prices of options that have more than 1 month to maturity are more sensitive to the state variables than are the prices of options that have less

\footnotetext{
${ }^{10}$ The signs of the correlations $\rho_{r m}, \rho_{\pi m}, \rho_{\eta m}$ have been changed from those reported in Brennan and Xia (2006, Table 6) to reflect the fact that the correlations reported there are with the negative of the innovation in $m$.
} 
than 1 month to maturity and, consistent with this, we find that when we restrict attention to the 2-month option returns we can reject the null for all the variables except $\Delta \eta$.

We use as instruments in our GMM regressions $\left(1, R_{f}, r, \pi, \eta, \sigma\right)$, a constant, the nominal interest rate, estimates of the instantaneous real interest rate and expected rate of inflation, the estimate maximum Sharpe ratio and the implied volatility of option returns. Regressions of the option portfolio returns on these variables yield $R^{2}$ of $4-10 \%$ in the UK and of $2-7 \%$ in the US, with the implied volatility being the most significant variable in both countries. A likelihood ratio test easily rejects the null hypothesis that the instruments jointly lack predictive power for the option portfolio returns.

Table 4 reports GMM estimates of the coefficients of the generalized isoelastic pricing kernel. ${ }^{11}$ These are estimated from the system of (empirical) moment conditions:

$$
\frac{1}{T} \sum_{t=1}^{T}\left[c_{0}\left(1+R_{W, t}\right)^{-\gamma} \exp ^{c_{1} \Delta r_{t}+c_{2} \Delta \eta_{t}+c_{3} \Delta \sigma_{t}}\left(1+R_{i, t)}\right)-1\right] z_{t-1}=0
$$

where $\gamma$ is the coefficient of relative risk aversion, $R_{i, t}$ is the return on each of the test assets (portfolios) in month $t$, and $z_{t-1}$ is the instrumental variable. The test assets are the option portfolios, aggregate wealth, and the Treasury Bill. We report the results using 11 option portfolios for the UK market and 10 portfolios for the US market, as discussed previously. For each sample we estimate three models. In the first specification, the pricing kernel is assumed to be an iso-elastic function of the aggregate wealth return only; this corresponds to the pricing kernel projections of Rosenberg and Engle (2002), Jackwerth (2000) and others for the S\&P 500, and of Liu et. al. (2006) for the FTSE index. The second model introduces the ICAPM state variables $r$ and $\eta$, and the third model includes, in addition, the implied volatility of the equity index, $\sigma$. The $t$-ratios reported in the estimations should be treated with some caution because of the extreme non-normality of the return data and the limited sample size. In the discussion that follows we shall take this caution as given. ${ }^{12}$

\footnotetext{
${ }^{11}$ The estimation was carried out in Eviews v5 updating the weighting matrix once.

${ }^{12}$ Ferson and Foerster (1994) discuss small sample biases in GMM estimates of an asset pricing model. Lynch and Wachter (2004) introduce GMM-based estimation methods when the sample data have unequal length. However, their methods do not lend themselves to our case, where the missing observations occur at random points in each series.
} 
Consider first the estimates for the UK reported in Panel A. For the first model of the pricing kernel, which excludes any state variables, the estimate of $\gamma$ is negative (around -0.3) and highly significant (t-ratio of 10.5). The negative estimates of $\gamma$ is inconsistent with risk aversion if the FTSE 250 index is taken as a proxy for aggregate wealth and if there is no variable other than the aggregate wealth return in the pricing kernel. In contrast, the estimate of $\gamma$ reported in Panel B for the US is positive and significant at 3.0 .

Consider next the effect of introducing the state variables $r$ and $\eta$ into the pricing kernel. Now the estimate of $\gamma$ for the UK is 2.3, although the estimated t-statistic is not large. The corresponding estimates for the US is $6.0 . .^{13}$

The estimated coefficient of $\Delta r$ is highly significant for both the US and the UK. The sign of the estimated coefficient is positive in both cases, which is consistent with the signs of the correlations estimated by Brennan and Xia (2006) from the bond yield data, reported in Table 2 Panel C, and also with the negative risk premium for interest rate risk found by BWX (2004, Table 2) for size and book-to-market sorted US stock portfolios. The sign of the parameter implies that there is a negative risk premium associated with being long ' $r$ ' risk, or a positive risk premium for securities such as bonds whose returns load negatively on the interest rate.

The coefficient of $\Delta \eta$ is negative and highly significant for the US estimations; this is again consistent with the sign of the estimate of $\rho_{\eta m}$ for the US in Table 2 Panel C, as well as with the BWX findings. However, the estimated coefficient of $\Delta \eta$ for the UK, while negative and therefore consistent with the sign of $\rho_{\eta m}$ estimated from UK government bond yields, is not significant.

When implied volatility is added to the pricing kernel, its coefficient is positive but statistically insignificant, and it does not change our qualitative remarks about the other coefficients. The positive sign of the coefficient on $\Delta \sigma$ implies a negative risk premium associated with a long position in volatility, which is consistent with the findings of Bakshi and Kapadia (2003)

\footnotetext{
${ }^{13}$ Mayfield (2004) reports estimates of the coefficient of relative risk aversion for the US of around unity in a model with changing volatility. The coefficient of risk aversion estimated in Coval and Shumway (2001) ranges from -6.68 to 6.0 depending on which US S\&P 500 option straddle is used in the estimation. Both Aït-Sahalia and Lo (2000) and Rosenberg and Engle (2002) use the US S\&P 500 index options to estimate empirical pricing kernels and the estimated risk aversion coefficient has an average value of 12.7 in Aït-Sahalia and Lo (2000) and of 7.36 in Rosenberg and Engle (2002).
} 
and Coval and Shumway (2001), who find that returns on market neutral straddles and other positions that are long volatility are negative.

In summary, we have found that if no state variable is included in the pricing kernel, the estimated iso-elastic kernel for the UK is inconsistent with risk aversion, but this inconsistency is eliminated with the inclusion of the state variables. All the US estimates are consistent with risk aversion. We have found that interest rate risk, ' $\eta$ ' risk, and volatility risk are priced consistently in the two countries. We conclude that if the pricing kernel is constrained to be of the iso-elastic form in the aggregate wealth return, then there is strong evidence that there are additional state variables in the pricing kernel in addition to aggregate wealth. The evidence is strongest for the interest rate, and is also strong for $\eta$ in the US. ${ }^{14}$

However, it is possible that these variables attain their significant role because of the constraint that we have imposed on the functional dependence of the pricing kernel on the aggregate wealth return. Therefore, we shall examine the effect of allowing more general functional forms for the return related element of the pricing kernel.

Bansal and Viswanathan (1993) argue that high-dimensional non-linear pricing kernels are necessary to price the non-linear payoffs of derivative assets, and use a neural network approach to approximate the unknown pricing kernel. Chapman (1997) and Rosenberg and Engel (2002) use orthogonal polynomials to approximate a nonlinear pricing kernel. We follow the latter and allow the wealth dependent element of the pricing kernel to be approximated by a sum of orthogonal polynomials in the aggregate wealth return. The pricing kernel is then written as the product of a sum of orthogonal polynomials in the aggregate wealth return and an exponential affine function of the state variables:

$$
m=\wp^{n}\left(R_{W}\right) \exp ^{c_{2} \Delta r+c_{3} \Delta \eta+c_{4} \Delta \sigma}
$$

where

$$
\wp^{n}\left(R_{W}\right)=\theta_{0} C_{0}\left(1+R_{W}\right)+\sum_{k=1}^{n} \theta_{k} C_{k}\left(1+R_{W}\right)
$$

is an $n$-term generalized Chebyshev polynomial ${ }^{15}$ expansion in the gross

\footnotetext{
${ }^{14}$ The results for separate estimations for the 1- and 2-month option portfolios, and for the call and put option portfolios are similar to those reported in Table 4 and are available upon request.

${ }^{15}$ There are several families of orthogonal polynomials. For example, Chapman (1997)
} 
return on aggregate wealth, $\left(1+R_{W}\right)$, and $C_{k}\left(1+R_{W}\right)$ stands for the $k^{\text {th }}$ order Chebyshev polynomial. The Chebyshev polynomial is defined over the domain [-1,1] with terms $C_{k}(x)=\cos \left(k \cos ^{-1}(x)\right)$. In the generalized Chebyshev polynomial, the gross return $1+R_{W}$, which is defined over the interval $[a, b]$, is first transformed into $x$ via $x=\frac{2\left(1+R_{W}\right)-a-b}{b-a}$ before $C_{k}(x)$ can be calculated. Following Rosenberg and Engle (2002), we set the return domain for the Chebyshev polynomial to be [0.9,1.1], and gross returns below (above) 0.9 (1.1) are set to 0.9 (1.1). We consider approximations with $n=3$, 4 terms of the gross return on aggregate wealth, $1+R_{W}$. While we do not restrict the pricing kernel to be strictly positive in our estimation, the estimated pricing kernels all turn out to be positive in the relevant region.

Table 5 reports the estimated coefficients of the state variables for two different specifications of the pricing kernel. Panel I of the table reports the results when $r$ and $\eta$ are the only state variables. The coefficient estimates are fairly insensitive to the degree of the approximating polynomial, and for the US the coefficients are very close to those reported for the iso-elastic kernel in Table 4. For both countries the coefficients of $\Delta r(\Delta \eta)$ are now positive (negative) and significant, which is consistent with the signs of $\rho_{r m}$ $\left(\rho_{\eta m}\right)$ as discussed above. When the implied volatility is introduced into the kernel in Panel II, its coefficient is positive and significant for both countries, which is also consistent with the results reported above for the iso-elastic kernel. However, for the UK the inclusion of implied volatility makes the coefficient of $\eta$ insignificant.

We expect the functions $g\left(R_{W}\right)$ to be monotone decreasing. When we estimate the kernel without including any state variables, $m=\wp^{3}\left(R_{W}\right)$, where $\wp^{3}\left(R_{W}\right)$ is a third order Chebychev polynomial, we find, as shown in Figure 1 , that the function is generally downward sloping for the US for market returns less than about $5 \%$ in absolute value. The function flattens out and even decreases for $\left|R_{W}\right|>5 \%$, but it is not well identified in this region. However, for the UK the function takes on the shape of an inverted ' $U$ ' which is clearly inconsistent with risk aversion. When the state variables are included in the pricing kernel, the wealth related component, $g\left(R_{W}\right)=\wp^{3}\left(R_{W}\right)$ is monotone decreasing for $\left|R_{W}\right|>5 \%$, and becomes close to monotone decreasing for the UK (it flattens out and is slightly increasing at the ends). Thus while the introduction of the state variables has only a modest effect on the function for the US, it has a major effect for the UK (as

uses a four-term Legendre polynomial to approximate the pricing kernel, and Rosenberg and Engle (2002) estimate the empirical pricing kernel with a three-term generalized Chebyshev polynomial expansion. 
we found for the iso-elastic specification) and makes the estimated pricing kernel broadly consistent with risk aversion.

\section{Conclusion}

In this paper we use returns on portfolios of FTSE 100 and S\&P 500 index options to estimate pricing kernels that depend, not only on the aggregate wealth return, but also on up to three state variables, the real interest rate, $r$, the maximum Sharpe ratio, $\eta$, and the implied volatility of option prices, $\sigma$. The first two state variables are derived from the BWX (2004) version of the ICAPM, as estimated by BX (2006) using data on government bond yields. The implied volatility is included as a state variable because previous studies have found evidence that hedged option portfolios that are formed to have a positive loading on volatility produce negative excess returns, and because of evidence that it is necessary to include this variable to capture the dynamics of the maximum Sharpe ratio, $\eta$. Preliminary regressions show that option returns are significant related to innovations to state variables, and the loadings differ across option type, moneyness, and time to maturity.

We estimate the pricing kernels by GMM using the returns on 11 (10) portfolios of UK (US) index options formed according to type, moneyness, and time to expiration. We express the pricing kernel as the product of a function of the aggregate wealth return and an exponential affine function of the changes in the state variables. The pricing kernel is first constrained to depend on a power function of the aggregate wealth return. When no state variables are included in the kernel, the estimated power is positive and highly significant for the UK, which is inconsistent with risk aversion. However, when the innovations of the state variables are included in the kernel, the estimate of the power becomes negative, although not significant. The state variable $r$ appears significantly in the pricing kernel, but neither the maximum Sharpe ratio $\eta$ nor the implied volatility $\sigma$ are significant. For the US, the estimated coefficient of relative risk aversion is 2.7 when no state variables are included, and 4.8 when $r, \eta$, and $\sigma$ are included. The coefficients of all three state variables are significant, and their signs are consistent with previous findings of a negative volatility premium, with the estimated correlations between the pricing kernel and $r$ and $\eta$ estimated from bond yields, and with the risk premia estimated using portfolios of common stocks by BWX.

It is possible that the significance of the state variables is due to the con- 
strained functional form of the dependence of the kernel on the aggregate wealth return. Therefore we repeat the estimations by substituting a polynomial expression in the return on wealth for the power function. The coefficients on the state variables for the US are essentially unaffected by the change in functional form of the kernel, and the coefficients of $\Delta r, \Delta \eta$, and $\Delta \sigma$ are consistent and significant across specifications. For the UK, the coefficients of $\Delta r$ and $\Delta \sigma$ are also consistent and significant across specifications. While the coefficient on $\Delta \eta$ in the US is negative and significant in all specifications the $\Delta \eta$ coefficient in the UK is not significant in the presence of $\Delta \sigma$. Finally, the signs of the coefficients of the state variables in the pricing kernel are consistent across countries, consistent with the signs of their correlations with the pricing kernel estimated from bond yields, and consistent with the BWX risk premium estimates.

The results in the paper provide further evidence that the failure of traditional asset pricing models is at least in part due to the failure to include in the pricing kernel non-wealth-related variables that are important to investors, because they describe future investment opportunities. This of course is the insight underlying Merton's (1973) classic analysis. However, the rejection of the over-identifying restrictions suggests that there are other variables than those we have considered that are important to investors. Longstaff (1995) suggests that transaction costs and liquidity effects are important for the pricing of index options, and Santa-Clara and Saretto (2005) point to the importance of margin requirements as obstacles to the achievement of equilibrium in options markets. 


\section{References}

Ait-Sahalia, Y., and A. Lo, 2000, Non-parametric risk management and implied risk aversion, Journal of Econometrics, 94, 9-51.

Bakshi, G., and N. Kapadia, 2003, Delta-hedged gains and the negative market volatility risk premium, Review of Financial Studies, 16, 527-566.

Bansal, R., and S. Viswanathan, 1993, No arbitrage and arbitrage pricing a new approach, Journal of Finance, 48, 1231-1262.

Bick, A., 1987, On the Consistency of the Black-Scholes Model with a General Equilibrium Framework, Journal of Financial and Quantitative Analysis, 22, 259-275.

Black, F., and M. Scholes, 1973, On the pricing of options and corporate liabilities, Journal of Political Economy, 81, 637-659.

Brandt, M.W., and Q. Kang, 2004, On the relationship between the conditional mean and volatility of stock returns: A latent VAR approach, Journal of Financial Economics, 72, 217-257.

Brennan, M. J., 1979, The Pricing of Contingent Claims in Discrete Time Models, Journal of Finance, 34, 53-68.

Brennan, M.J., A. W. Wang, and Y. Xia, 2004, Estimation and test of a simple model of intertemporal capital asset pricing, Journal of Finance, 59, 1743-1775.

Brennan, M.J., and Y. Xia, 2006, International Capital Markets and Foreign Exchange Rate Risk, Review of Financial Studies, forthcoming.

Buraschi, A., and J. Jackwerth, 1999, Is Volatility Risk Priced in Option Markets?, unpublished manuscript, London Business School.

Campbell, J., Lo, A., MacKinlay, C., 1997. The Econometrics of Financial Markets. Princeton University Press, Princeton, NJ.

Chapman, D. A., 1997, Approximating the Asset Pricing Kernel, Journal of Finance, 52, 1383-1410.

Chernov, M., A.R. Gallant, E. Ghysels, and G. Tauchen, 2003, Alternative Models for Stock Price Dynamics, Journal of Econometrics, 116, 225-258.

Cochrane, J. H., 2001, Asset Pricing, Princeton University Press, Princeton, N.J. 
Coval, J.D., and T. Shumway, 2001, Expected Option Returns, Journal of Finance, 56, 983-1010.

Driessen, J., and P. Maenhout, 2003, A Portfolio Perspective on Option Pricing Anomalies, working paper, INSEAD.

Fama, E.F., and K. R. French, 1995, Size and book-to-market factors in earnings and returns, Journal of Finance, 50, 131-156.

Ferson, W., and S.R. Foerster, 1994, Finite sample properties of the Generalized Method of Moments in test of conditional asset pricing models, Journal of Financial Economics, 36, 29-56.

Jackwerth, J.C., 2000, Recovering risk aversion from option prices and realized returns, Review of Financial Studies, 13, 433 - 451.

Liu, X., M.B. Shackleton, S.J. Taylor, and X. Xu, 2006, Closed-form transformations from risk-neutral to real-world distributions, Working paper, Lancaster University.

Longstaff, F.A., 1995, Option pricing and the martingale restriction, Review of Financial Studies, 8, 1091 - 1124.

Lynch, A., and J. Wachter, 2004, Using Samples of Unequal Length in Generalized Method of Moments Estimation, working paper, University of Pennsylvania.

Mayfield, E. S., 2004, Estimating the market risk premium, Journal of Financial Economics, 73, 465-496.

Merton, R., 1973, An intertemporal capital asset pricing model, Econometrica, 41, 867-888.

Nielsen, L. T. and M. Vassalou, 2005, Portfolio selection with randomly time-varying moments: the role of the instantaneous capital market line, forthcoming Economic Theory.

Pan, J., 2002, The Jump-Risk Premia Implicit in Options: Evidence from an Integrated Time-Series Study, Journal of Financial Economics, 63, 3-50.

Rosenberg, J. V., and R. F. Engle, 2002, Empirical pricing kernels, Journal of Financial Economics, 64, 341-372.

Rubinstein, M., 1976, The valuation of options and the pricing of uncertain income streams, Bell Journal of Economics and Management Science, 7, 407-425. 
Santa-Clara, P., and S. Yan, 2004, Jump and Volatility Risk and Risk Premia: A New Model and Lessons from the S\&P 500 Options, working paper, The Anderson School, UCLA.

Santa-Clara, P., and A. Saretto, 2005, Option Strategies: Good Deals and Margin Calls, working paper, Anderson School, UCLA.

Tauchen, G., 2005, Stochastic Volatility in General Equilibrium, working paper, Duke University.

Vanden, J. M., 2004, Option trading and the CAPM, Review of Financial Studies, 17, 207-238. 


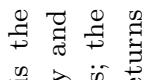

$\therefore \stackrel{B}{\Rightarrow}$ की

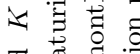

䒕 ๕્व

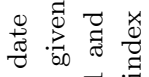

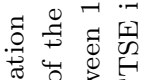

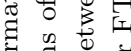

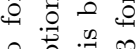

융

范

원

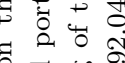

○ उ

过

30.

吾焉

항

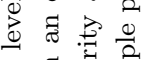

త 0 :

ฯ

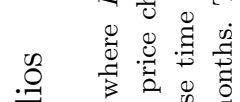

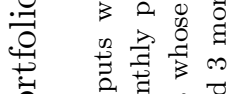

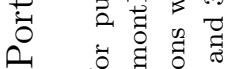

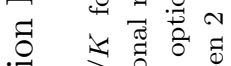

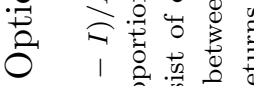

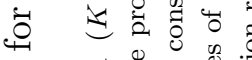

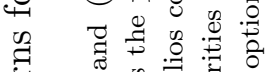

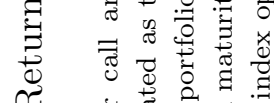

山 के

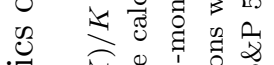

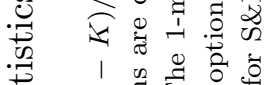

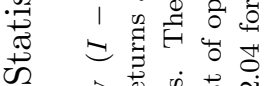

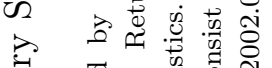

范

छ $\quad$ 过

ש . .

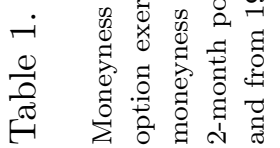

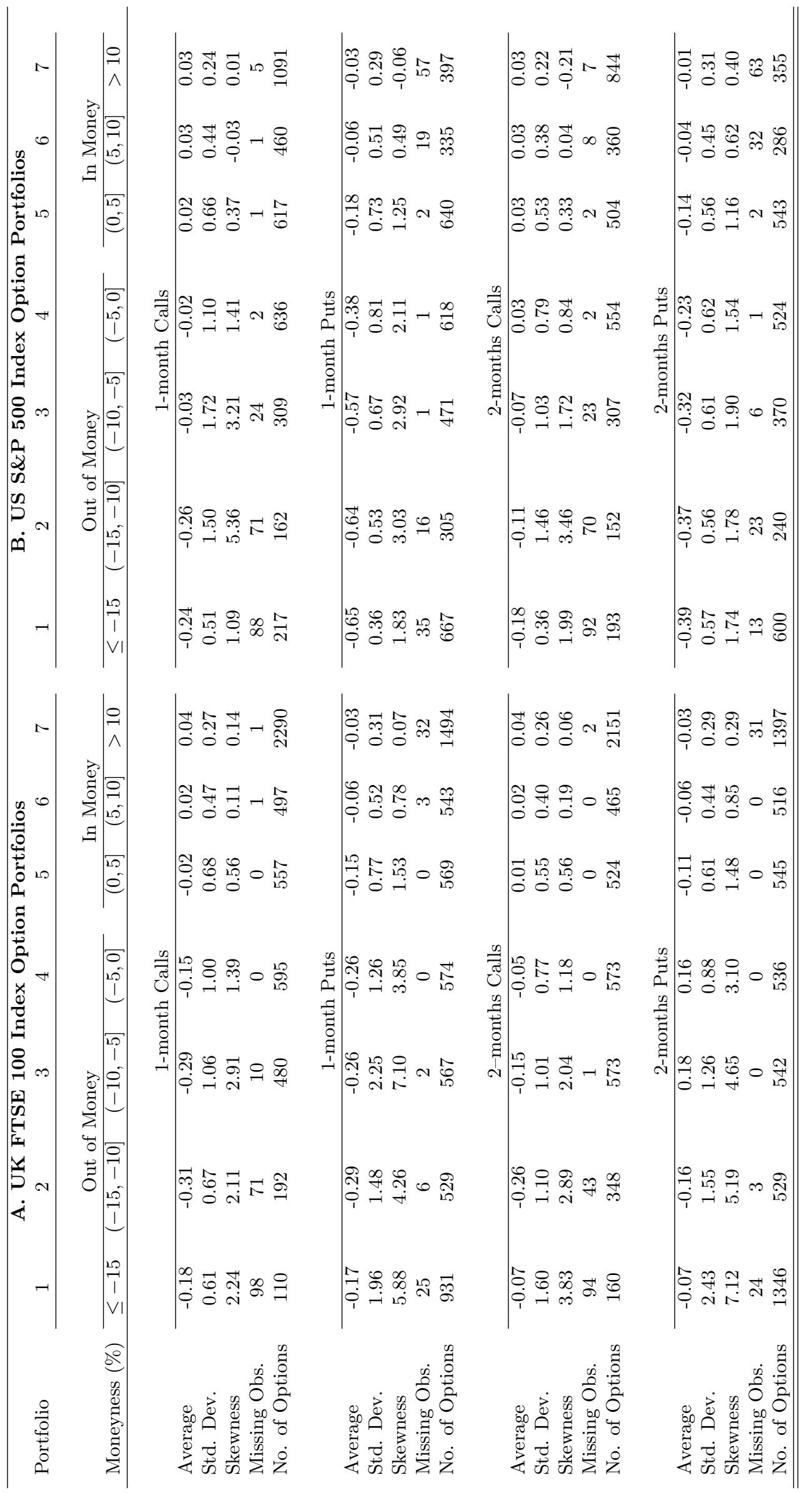


Table 2. Summary Statistics of Pricing Kernel Arguments and Instruments

Panel A reports the mean, standard deviation, and skewness of the risk free rate, the market return, the level and the innovations of the state variables $r, \pi, \eta$, and $\sigma$. Panel B reports the contemporaneous correlations between the market return and the innovations in $r, \pi, \eta$ and $\sigma$. Panel $\mathrm{C}$ reports the correlation between innovations of the state variables and the pricing kernel $m$, as estimated in Brennan and Xia (2006). All variables are annualized.

Panel A: Mean, Standard Deviation, and Skewness

\begin{tabular}{llllllllll}
\hline$r$ & $\Delta r$ & $\eta$ & $\Delta \eta$ & $\sigma$ & $\Delta \sigma$ & $\pi$ & $\Delta \pi$ & $R_{f}$ & $R_{W}$ \\
\hline
\end{tabular}

1. United Kingdom

$\begin{array}{ccccccccccc}\text { Mean } & 0.034 & -0.000 & 0.728 & -0.002 & 0.217 & 0.022 & 0.027 & -0.000 & 0.062 & 0.125 \\ \text { Stdev } & 0.024 & 0.003 & 0.882 & 0.069 & 0.072 & 0.035 & 0.023 & 0.003 & 0.013 & 0.148 \\ \text { Skew } & -0.045 & -2.051 & 0.120 & 0.416 & 1.054 & 0.800 & -0.172 & 0.102 & 1.313 & -0.109\end{array}$

\section{United States}

$\begin{array}{lcccccccccc}\text { Mean } & 0.023 & -0.000 & -0.063 & -0.001 & 0.193 & 0.000 & 0.028 & -0.000 & 0.052 & 0.117 \\ \text { Stdev } & 0.014 & 0.003 & 0.338 & 0.030 & 0.060 & 0.036 & 0.005 & 0.001 & 0.005 & 0.146 \\ \text { Skew } & 0.397 & -0.338 & -0.105 & 0.955 & 0.699 & -0.196 & -0.204 & 0.230 & 0.280 & -0.818\end{array}$


Table 2 continued

Panel B: Contemporaneous Correlations

\begin{tabular}{|c|c|c|c|c|c|c|c|c|c|c|c|}
\hline & \multicolumn{5}{|c|}{ 1. United Kingdom } & & \multicolumn{5}{|c|}{ 2. United States } \\
\hline & $\Delta r$ & $\Delta \eta$ & $\Delta \sigma$ & $\Delta \pi$ & $R_{W}$ & & $\Delta r$ & $\Delta \eta$ & $\Delta \sigma$ & $\Delta \pi$ & $R_{W}$ \\
\hline$\Delta r$ & 1.0 & & & & & $\Delta r$ & 1.0 & & & & \\
\hline$\Delta \eta$ & -0.08 & 1.0 & & & & $\Delta \eta$ & -0.24 & 1.0 & & & \\
\hline$\Delta \sigma$ & 0.22 & -0.08 & 1.0 & & & $\Delta \sigma$ & -0.05 & -0.08 & 1.0 & & \\
\hline$\Delta \pi$ & -0.45 & 0.18 & -0.02 & 1.0 & & $\Delta \pi$ & 0.23 & 0.13 & -0.04 & 1.0 & \\
\hline$R_{W}$ & -0.17 & -0.09 & -0.44 & -0.14 & 1.0 & $R_{W}$ & 0.09 & -0.16 & -0.49 & -0.02 & 1.0 \\
\hline
\end{tabular}

Panel C: Correlations between innovations in state variables and $m$

1. United Kingdom

$\begin{array}{lcccccc} & \rho_{r \pi} & \rho_{r \eta} & \rho_{r m} & \rho_{\pi \eta} & \rho_{\pi m} & \rho_{\eta m} \\ \text { Estimate } & -0.104 & -0.234 & 0.714 & -0.191 & -0.178 & -0.833 \\ \text { t-ratio } & (0.75) & (1.14) & (3.49) & (0.78) & (1.93) & (4.38)\end{array}$

2. United States

\begin{tabular}{lcccccc} 
& $\rho_{r \pi}$ & $\rho_{r \eta}$ & $\rho_{r m}$ & $\rho_{\pi \eta}$ & $\rho_{\pi m}$ & $\rho_{\eta m}$ \\
Estimate & 0.027 & -0.413 & 0.801 & -0.199 & 0.276 & -0.919 \\
t-ratio & $(0.11)$ & $(0.54)$ & $(6.22)$ & $(0.69)$ & $(1.66)$ & $(2.57)$ \\
\hline \hline
\end{tabular}




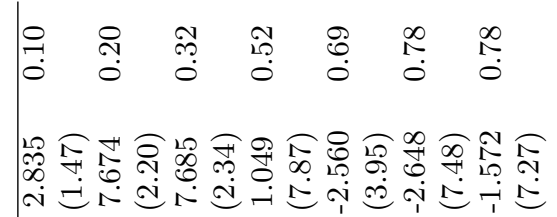
थ

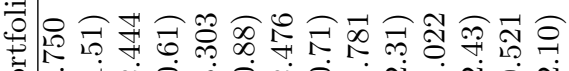
Q

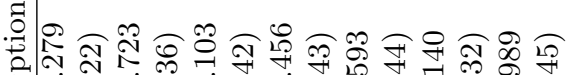

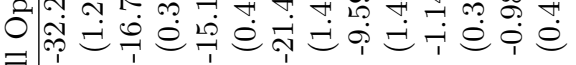
ขึ)

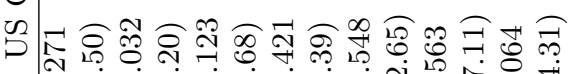

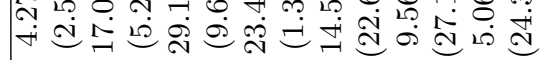
次等 i vid

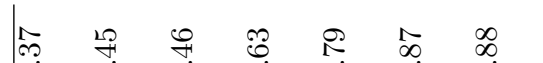
$\because 0000000$

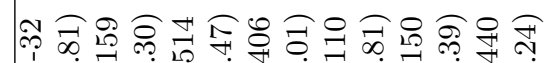

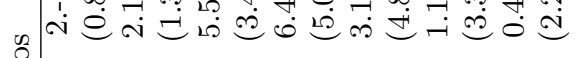

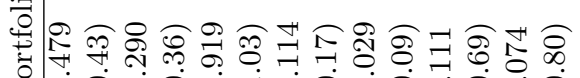

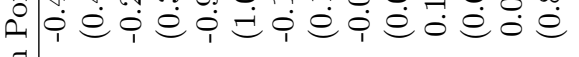

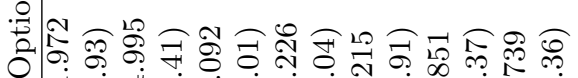

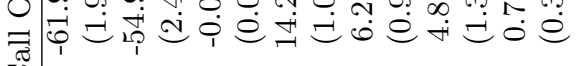

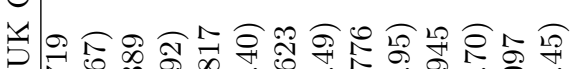

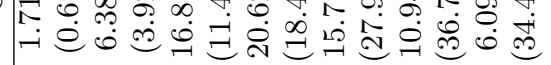

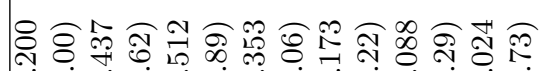
i i

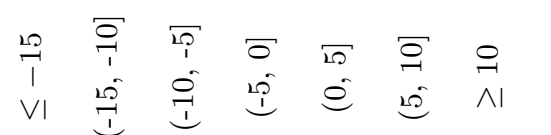

$\mid \begin{array}{lllllll}\Lambda & 0 & 0 & 1 & 0 & 0 & 0 \\ 0 & 0 & 0 & 0 & 0 & 0 & 0 \\ 0 & 0 & 0 & 0 & 0 & 0 & 0\end{array}$

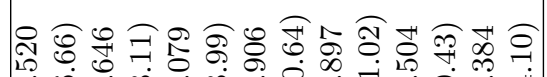
+

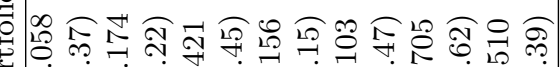
开

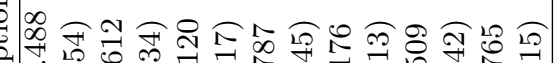

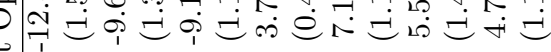
क

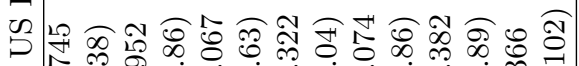
ণ

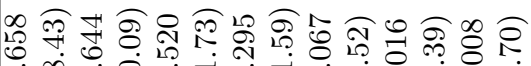

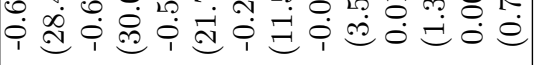

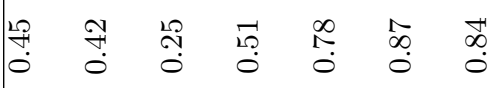

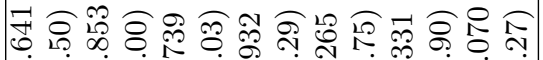
(s)

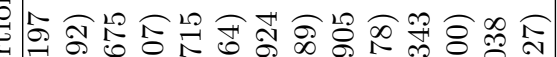
龶

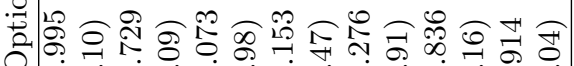

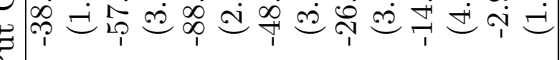

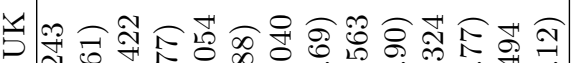
过

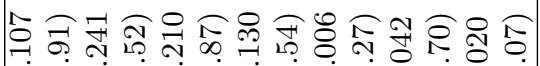
i é 


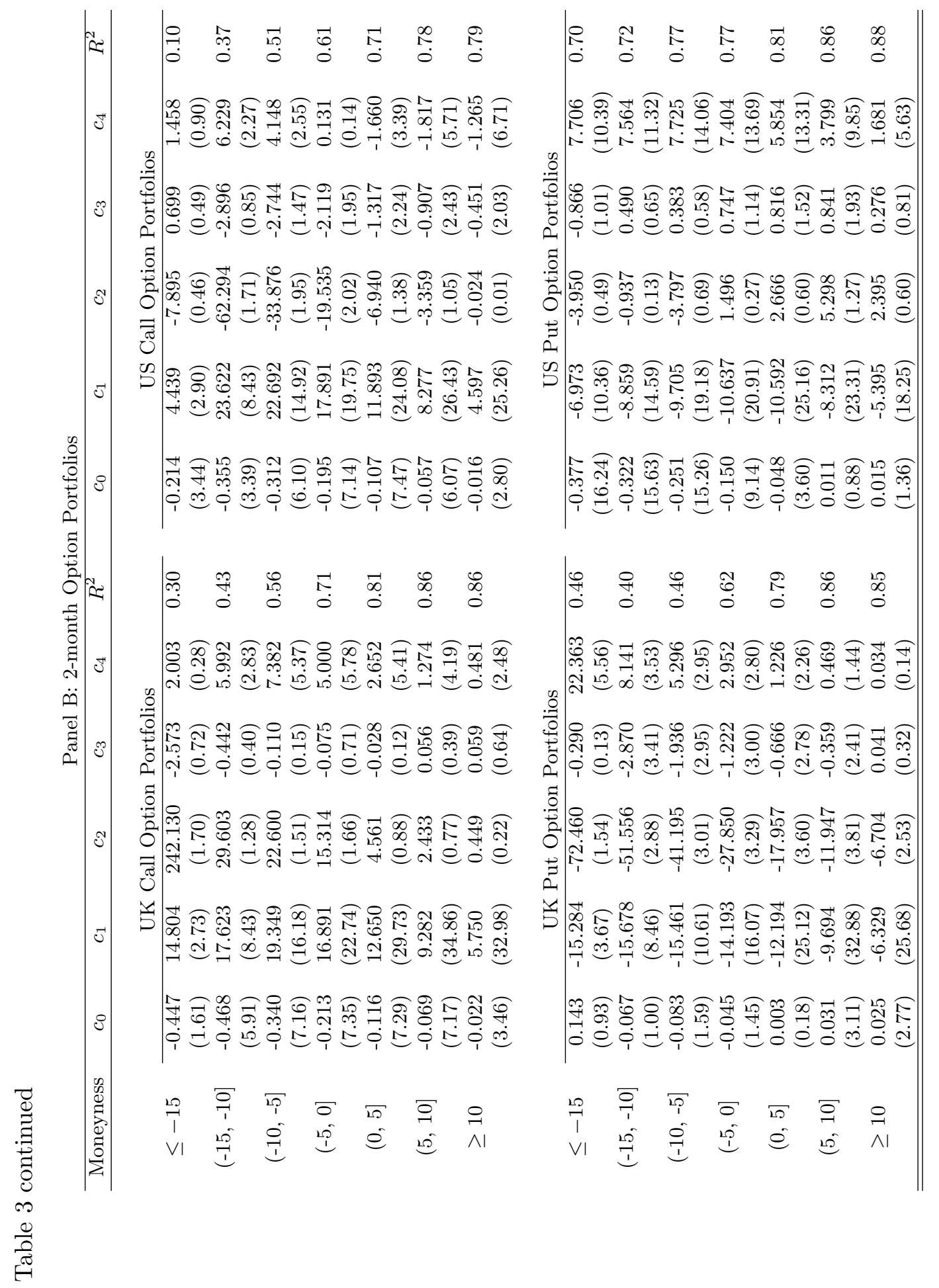


Table 4. GMM Estimates of Iso-Elastic Pricing Kernels

The table reports GMM estimates of iso-elastic pricing kernels for monthly returns on option portfolios, the market index returns, and the Treasury bill rate. The general pricing kernel equation is of the form:

$$
m=c_{0}\left(1+R_{W}\right)^{-\gamma} e^{c_{1} \Delta r+c_{2} \Delta \eta+c_{3} \Delta \sigma}
$$

The option portfolios contain options with maturities of between 1 and 2 months, and between 2 and 3 months and with different moneyness. The sample period is 1992.04 to 2002.03 with 1560 observations for Panel A and 1992.01 to 2002.04 with 1473 observations for Panel B.

\begin{tabular}{ccccc}
\hline \hline \multicolumn{5}{c}{ Panel A. UK FTSE 100 Option Portfolios } \\
\hline$c_{o}$ & $\gamma$ & $c_{1}$ & $c_{2}$ & $c_{3}$ \\
\hline & & & \\
1.005 & -0.276 & & & \\
$(2236)$ & $(10.49)$ & & & \\
0.910 & 2.265 & 189.805 & -0.141 & \\
$(38.36)$ & $(1.53)$ & $(4.89)$ & $(0.28)$ & \\
0.886 & 1.171 & 204.052 & -0.065 & 1.520 \\
$(32.71)$ & $(0.51)$ & $(5.18)$ & $(0.13)$ & $(0.89)$ \\
& & & & \\
\hline
\end{tabular}

Panel B. US S\&P 500 Option Portfolios

\begin{tabular}{ccccc}
\hline$c_{o}$ & $\gamma$ & $c_{1}$ & $c_{2}$ & $c_{3}$ \\
\hline & & & & \\
1.064 & 2.688 & & & \\
$(585)$ & $(15.73)$ & & & \\
0.793 & 5.994 & 112.137 & -23.734 & \\
$(11.98)$ & $(3.03)$ & $(3.29)$ & $(4.06)$ & \\
0.670 & 4.758 & 131.648 & -29.034 & 3.342 \\
$(9.63)$ & $(2.20)$ & $(3.38)$ & $(4.52)$ & $(1.89)$ \\
& & & & \\
\hline \hline
\end{tabular}


Table 5. GMM Estimates of Polynomial Pricing Kernels

The table reports GMM estimates of polynomial pricing kernels for monthly returns on option portfolios, the market index returns, and the Treasury bill rate. The general pricing kernel equation is of the form:

$$
m=\wp^{n}\left(R_{W}\right) e^{c_{1} \Delta r+c_{2} \Delta \eta+c_{3} \Delta \sigma}
$$

The option portfolios contain options with maturities of between 1 and 2 months, and between 2 and 3 months and with different moneyness. The sample period is 1992.04 to 2002.03 for Panel A and 1992.01 to 2002.04 for Panel B.

\begin{tabular}{|c|c|c|c|c|c|c|}
\hline \multirow[b]{2}{*}{$\mathrm{n}$} & \multicolumn{3}{|c|}{ A. UK option portfolios } & \multicolumn{3}{|c|}{ B. US option portfolios } \\
\hline & $c_{1}$ & $c_{2}$ & $c_{3}$ & $c_{1}$ & $c_{2}$ & $c_{3}$ \\
\hline \multicolumn{7}{|c|}{ I. $m=\wp^{n}\left(R_{W}\right) e^{c_{1} \Delta r+c_{2} \Delta \eta}$} \\
\hline 3 & $\begin{array}{c}251.83 \\
(5.91)\end{array}$ & $\begin{array}{l}-1.25 \\
(2.20)\end{array}$ & & $\begin{array}{l}75.48 \\
(2.34)\end{array}$ & $\begin{array}{c}-20.48 \\
(3.72)\end{array}$ & \\
\hline 4 & $\begin{array}{c}274.36 \\
(6.45)\end{array}$ & $\begin{array}{l}-1.55 \\
(2.70)\end{array}$ & & $\begin{array}{l}82.71 \\
(1.97)\end{array}$ & $\begin{array}{c}-110.25 \\
(9.52)\end{array}$ & \\
\hline \multicolumn{7}{|c|}{ II. $m=\wp^{n}\left(R_{W}\right) e^{c_{1} \Delta r+c_{2} \Delta \eta+c_{3} \Delta \sigma}$} \\
\hline 3 & $\begin{array}{l}395.97 \\
(8.66)\end{array}$ & $\begin{array}{c}-0.63 \\
(0.98)\end{array}$ & $\begin{array}{c}6.43 \\
(3.30)\end{array}$ & $\begin{array}{l}126.26 \\
(2.70)\end{array}$ & $\begin{array}{l}-41.42 \\
(5.57)\end{array}$ & $\begin{array}{c}0.06 \\
(2.57)\end{array}$ \\
\hline 4 & $\begin{array}{c}395.71 \\
(8.65)\end{array}$ & $\begin{array}{l}-0.69 \\
(1.05)\end{array}$ & $\begin{array}{c}6.17 \\
(2.32)\end{array}$ & $\begin{array}{c}173.24 \\
(3.29)\end{array}$ & $\begin{array}{r}-49.76 \\
(5.70)\end{array}$ & $\begin{array}{c}0.12 \\
(3.94)\end{array}$ \\
\hline
\end{tabular}


Figure 1. Return related element of estimated iso-elastic and polynomial pricing kernels

The figure plots the market return related component of the pricing kernel. Three $g\left(R_{W}\right)$ are plotted: (1) $g_{1}\left(R_{W}\right)$ is calculated from 3-term Chebyshev polynomials without any state variables; $(2) g_{2}\left(R_{W}\right)$ is calculated from 3-term Chebyshev polynomials with all three state variables; $(3) g_{3}\left(R_{W}\right)$ is estimated from iso-elastic pricing kernel with $\gamma=1.17$ for the UK market and $\gamma=4.76$ for the US market.
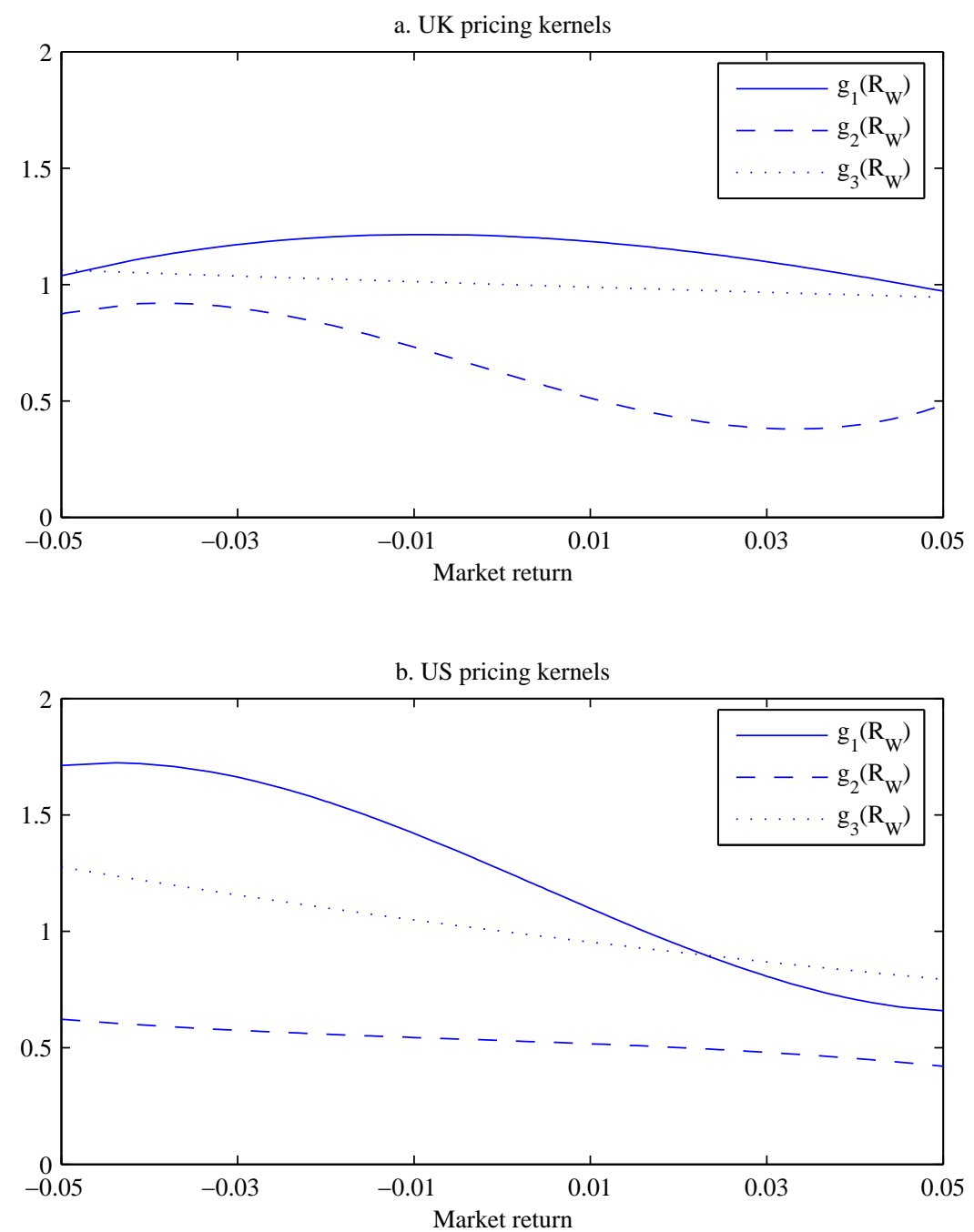